\title{
The Clinical Influence of the CONUT Score on Survival of Patients With Gastric Cancer Receiving Curative Treatment
}

\author{
TORU AOYAMA ${ }^{1,2^{*}}$, KEISUKE KOMORI $^{1,2^{*}}$, MASATO NAKAZANO ${ }^{1,2}$, KENTARO HARA $^{1,2}$, \\ HIROSHI TAMAGAWA ${ }^{1}$, KEISUKE KAZAMA ${ }^{1}$, ITARU HASHIMOTO ${ }^{1,2}$, TAKANOBU YAMADA ${ }^{1,2}$, \\ YUKIO MAEZAWA ${ }^{1,2}$, KENKI SEGAMI ${ }^{1,2}$, KAZUKI KANO $^{1}$, SHINSUKE NAGASAWA $^{1,2}$, NORIO YUKAWA ${ }^{1}$, \\ YASUSHI RINO ${ }^{1}$, TAKASHI OGATA ${ }^{2}$ and TAKASHI OSHIMA ${ }^{1,2}$ \\ ${ }^{1}$ Department of Surgery, Yokohama City University, Yokohama, Japan; \\ ${ }^{2}$ Department of Gastrointestinal Surgery, Kanagawa Cancer Center, Yokohama, Japan
}

\begin{abstract}
Background: We investigated the influence of the preoperative Controlling Nutritional Status (CONUT) score on survival and recurrence of gastric cancer in patients after curative treatment. Patients and Methods: This study included 331 patients who underwent curative surgery followed by adjuvant treatment for gastric cancer between 2013 and 2017. The risk factors for overall survival (OS) and recurrence-free survival (RFS) were identified. Results: Based on the 1-, 3- and 5-year survival rates, a CONUT score of 2 was regarded as the optimal cut-off value for classification. The 3- and 5-year OS rates were $93.6 \%$ and $88.6 \%$, respectively in the low-CONUT group, and $82.7 \%$ and $73.6 \%$ in high-CONUT group $(p=0.022)$. The 3 - and 5 year RFS rates were $78.8 \%$ and $68.7 \%$, respectively, in the low-CONUT group, and $89.3 \%$ and $86.6 \%$, respectively, in the high-CONUT group $(p=0.05)$. A multivariate analysis showed that the CONUT score was a significant independent predictive factor for OS and RFS. Conclusion: The CONUT score was a predictive factor for survival in patients who underwent curative treatment for gastric cancer. It is necessary to develop an effective plan for perioperative care and surgical strategy according to the CONUT score.
\end{abstract}

Gastric cancer is the third-most common cancer and the second leading cause of cancer-related death in the world

This article is freely accessible online.

*These Authors contributed equally to this study.

Correspondence to: Toru Aoyama, Department of Surgery, Yokohama City University, 3-9 Fukuura, Kanazawa-ku, Yokohama 236-0004, Japan. E-mail: t-aoyama@lilac.plala.or.jp

Key Words: Gastric cancer, CONUT score, survival.
(1, 2). Gastrectomy with D2 lymphadenectomy and perioperative adjuvant treatment is a standard treatment for resectable gastric cancer. However, even when patients receive curative treatment, more than half develop recurrent disease (3-5). Thus, to further improve the chance of survival, it is necessary to establish new approaches for treatment.

Previous studies showed that perioperative malnutrition affected short-term oncological outcomes, including postoperative surgical complications, the incidence of adverse events in patients who received adjuvant treatment, and the continuation of adjuvant treatment (6-9). Moreover, perioperative malnutrition also affected the long-term oncological outcomes in gastric cancer $(10,11)$. To evaluate the perioperative nutritional status and detect malnutrition, several markers of nutritional status, including the Geriatric Nutritional Risk Index, subjective global assessment, and mini nutritional assessment, were developed and are clinically used in gastrointestinal cancer treatment (12-14).

Recently, the controlling nutritional status (CONUT) score has been developed and used in screening of the perioperative nutritional status and assessment of malnutrition in cancer treatment (15). The CONUT score is calculated from the serum albumin concentration, the total peripheral lymphocyte count, and the total cholesterol concentration. Recent studies on the CONUT score in various malignancies have demonstrated that a high CONUT score is associated with poor oncological outcomes for many tumor types, including gastrointestinal tumors (16, 17). However, while the CONUT score has clinical advantages, such as cost effectiveness and simplicity, few studies have evaluated its prognostic value in patients with gastric cancer $(18,19)$. Therefore, we clarified whether or not the long-term oncological outcomes were affected by the CONUT score in patients with gastric cancer who underwent curative treatment. 
Table I. Comparison of overall survival rates stratified by patient characteristics.

\begin{tabular}{|c|c|c|c|c|c|c|}
\hline \multirow[b]{2}{*}{ Characteristics } & \multirow[b]{2}{*}{ Subgroup } & \multirow[b]{2}{*}{ No. of patients $(\%)$} & \multicolumn{3}{|c|}{ Survival rate, $\%$} & \multirow[b]{2}{*}{$p$-Value } \\
\hline & & & 1-Year & 3-Year & 5-Year & \\
\hline \multirow[t]{2}{*}{ Age } & $<65$ Years & $237(71.6 \%)$ & 97.0 & 88.1 & 82.3 & 0.260 \\
\hline & $\geq 65$ Years & $94(28.4 \%)$ & 98.9 & 94.7 & 84.9 & \\
\hline \multirow[t]{2}{*}{ Gender } & Male & $219(66.2 \%)$ & 97.3 & 88.5 & 82.2 & 0.223 \\
\hline & Female & $112(33.8 \%)$ & 98.2 & 92.8 & 86.5 & \\
\hline \multirow[t]{2}{*}{ Pathological type } & Intestinal & $172(52.0 \%)$ & 98.8 & 93.6 & 87.5 & 0.038 \\
\hline & Diffuse & $159(48.0 \%)$ & 96.2 & 85.4 & 79.6 & \\
\hline \multirow[t]{2}{*}{ Pathological $\mathrm{T}$ status } & $\mathrm{T} 1$ & $206(62.2 \%)$ & 99.0 & 95.6 & 92.1 & $<0.001$ \\
\hline & $\mathrm{T} 2$ to $\mathrm{T} 4$ & $125(37.1 \%)$ & 96.0 & 80.8 & 69.9 & \\
\hline \multirow{2}{*}{ Pathological lymph node metastasis } & Negative & $233(70.4 \%)$ & 98.3 & 96.1 & 92.1 & $<0.001$ \\
\hline & Positive & $98(39.6 \%)$ & 95.9 & 74.3 & 63.5 & \\
\hline \multirow[t]{2}{*}{ CONUT score } & $<2$ & $221(66.8 \%)$ & 98.2 & 93.6 & 88.6 & $<0.001$ \\
\hline & $\geq 2$ & $110(33.2 \%)$ & 96.4 & 82.7 & 73.6 & \\
\hline \multirow[t]{2}{*}{ Lymphatic invasion } & Negative & $226(68.3 \%)$ & 97.3 & 92.9 & 89.7 & $<0.001$ \\
\hline & Positive & $105(31.7 \%)$ & 98.1 & 82.7 & 67.8 & \\
\hline \multirow[t]{2}{*}{ Vascular invasion } & Negative & $192(58.0 \%)$ & 98.4 & 95.8 & 90.8 & $<0.001$ \\
\hline & Positive & $139(42.0 \%)$ & 96.4 & 81.2 & 72.3 & \\
\hline \multirow{2}{*}{ Postoperative surgical complications } & No & $281(84.9 \%)$ & 97.5 & 90.0 & 83.6 & 0.675 \\
\hline & Yes & $50(15.1 \%)$ & 98.0 & 87.8 & 80.0 & \\
\hline
\end{tabular}

CONUT: Controlling Nutritional Status.

\section{Patients and Methods}

Patients. Patients who underwent curative resection for gastric cancer at Kanagawa Cancer Center from 2013 to 2017 were selected based on medical records. The inclusion criteria were as follows: (i) histologically proven adenocarcinoma, (ii) clinical stage I-III disease, according to the fifth edition of the General Rules for Gastric Cancer published by the Japanese Gastric Cancer Association (20), and (iii) complete (R0) resection of gastric cancer with radical lymph node dissection.

Surgical procedure and adjuvant treatment. All patients underwent distal or total gastrectomy with lymphadenectomy. D1+ nodal dissection was performed for clinical stage IA disease, while D2 dissection was performed for clinical stage $\geq \mathrm{IB}$ disease. Patients diagnosed with pathological stage II or III disease received adjuvant chemotherapy for 1 year.

Evaluations and statistical analyses. The CONUT score was calculated using three parameters: Serum albumin, total cholesterol level, and total lymphocyte count. Serum albumin was categorized and scored as: score 0: $3.5-4.5 \mathrm{~g} / \mathrm{dl}$, score 2 : 3.0-3.49 $\mathrm{g} / \mathrm{dl}$, score 4: 2.5-2.9 g/dl, and score 6: $<2.5 \mathrm{~g} / \mathrm{dl}$. Total lymphocyte count was categorized and scored as: score 0 : $>1,600 / \mathrm{ml}$, score 1: $1,200-1,599 / \mathrm{ml}$, score 2: $800-1,199 / \mathrm{ml}$, and score $3:<800 / \mathrm{ml}$. Cholesterol was categorized and scored as: score 0: >180 mg/dl, score 1: $140-180 \mathrm{mg} / \mathrm{dl}$, score 2: 100-139 mg/dl, and score 3: $<100 \mathrm{mg} / \mathrm{dl}$. Blood samples were collected at day 17 before surgery. These individual scores were summed to provide a total CONUT score. The significance of differences in CONUT score and clinicopathological parameters was determined using the chi-squared test. Recurrence-free survival (RFS) was defined as the period between surgery and recurrence or death, whichever came first. Overall survival (OS) was defined as the period between surgery and death. The Kaplan-Meier method was used to calculate the OS and RFS curves. Univariate and multivariate survival analyses were performed using a Cox proportional hazards model. $p$-Values of 0.05 or less were considered to indicate statistical significance. The SPSS software program (v27.0 J Win; IBM, Armonk, NY, USA) was used for all statistical analyses. This study was approved by the IRB of Kanagawa Cancer Center (2019-eki-176).

\section{Results}

Patients. A total of 331 patients were evaluated. The cut-off value for the CONUT score was set at 2 based on the 3-and 5 -year OS rates (Table I) and the results of previous studies (16-19). The study population included 221 patients with a CONUT score of $<2$ (low-CONUT group) and 110 with a CONUT score of $\geq 2$ (high-CONUT group). Significant differences were observed in the following background characteristics of the low-CONUT and high-CONUT groups: median age $[65$ (range=36-84) versus 71 years (range=36-87) years; $p<0.001$ ]; preoperative albumin [26.3 (range=12.8-41.8) versus $22.7 \quad$ (range=10.8-47) $\mathrm{mg} / \mathrm{dl} ; \quad p<0.001]$, and preoperative C-reactive protein $[0.15$ (range $=0.01-3-17 \mathrm{mg} / \mathrm{l}$ ) versus 0.28 (range $=0-3-55$ ) $\mathrm{mg} / \mathrm{l} ; p=0.006]$. The high-CONUT group included a larger percentage of elderly patients and patients with a hyper-inflammatory status before surgery.

Survival analysis and patterns of recurrence. The clinicopathological factors were categorized and analyzed 
Table II. Univariate and multivariate Cox proportional hazards analysis of clinicopathological factors for overall survival.

\begin{tabular}{|c|c|c|c|c|c|c|c|c|}
\hline \multirow[b]{2}{*}{ Characteristic } & \multirow[b]{2}{*}{ Subgroup } & \multirow[b]{2}{*}{$\mathrm{n}$} & \multicolumn{3}{|c|}{ Univariate analysis } & \multicolumn{3}{|c|}{ Multivariate analysis } \\
\hline & & & OR & $95 \% \mathrm{CI}$ & $p$-Value & OR & $95 \% \mathrm{CI}$ & $p$-Value \\
\hline \multirow[t]{2}{*}{ Age } & $<65$ Years & 237 & 1.000 & & & & & \\
\hline & $\geq 65$ Years & 94 & 1.377 & $0.721-2.631$ & 0.332 & & & \\
\hline \multirow[t]{2}{*}{ Gender } & Male & 219 & 1.000 & & & & & \\
\hline & Female & 112 & 1.385 & $0.749-2.562$ & 0.299 & & & \\
\hline \multirow[t]{2}{*}{ Pathological type } & Intestinal & 172 & 1.000 & & & & & \\
\hline & Diffuse & 159 & 1.672 & $0.957-2.922$ & 0.071 & & & \\
\hline \multirow{2}{*}{$\begin{array}{l}\text { Pathological } \\
\text { T status }\end{array}$} & $\mathrm{T} 1$ & 206 & 1.000 & & & & & \\
\hline & $\mathrm{T} 2$ to $\mathrm{T} 4$ & 125 & 4.226 & $2.336-7.643$ & $<0.001$ & & & \\
\hline \multirow{2}{*}{$\begin{array}{l}\text { Lymph node } \\
\text { metastasis }\end{array}$} & Negative & 233 & 1.000 & & & 1.000 & & \\
\hline & Positive & 98 & 5.417 & $3.043-9.646$ & $<0.001$ & 3.464 & $1.864-6.440$ & $<0.001$ \\
\hline \multirow[t]{2}{*}{ CONUT score } & $<2$ & 221 & 1.000 & & & 1.000 & & \\
\hline & $\geq 2$ & 110 & 2.898 & $1.664-5.045$ & $<0.001$ & 1.949 & $1.100-3.451$ & 0.022 \\
\hline \multirow{2}{*}{$\begin{array}{l}\text { Lymphatic } \\
\text { invasion }\end{array}$} & Negative & 226 & 1.000 & & & & & \\
\hline & Positive & 105 & 3.189 & $1.829-5.559$ & $<0.001$ & & & \\
\hline \multirow{2}{*}{$\begin{array}{l}\text { Vascular } \\
\text { invasion }\end{array}$} & Negative & 192 & 1.000 & & & 1.000 & & \\
\hline & Positive & 139 & 4.239 & $2.290-7.846$ & $<0.001$ & 2.640 & $1.376-5.066$ & 0.003 \\
\hline \multirow{2}{*}{$\begin{array}{l}\text { Postoperative } \\
\text { complications }\end{array}$} & No & 281 & 1.000 & & & & & \\
\hline & Yes & 50 & 1.221 & $0.594-2.510$ & 0.586 & & & \\
\hline
\end{tabular}

CI: Confidence interval; CONUT: Controlling Nutritional Status; OR: odds ratio.

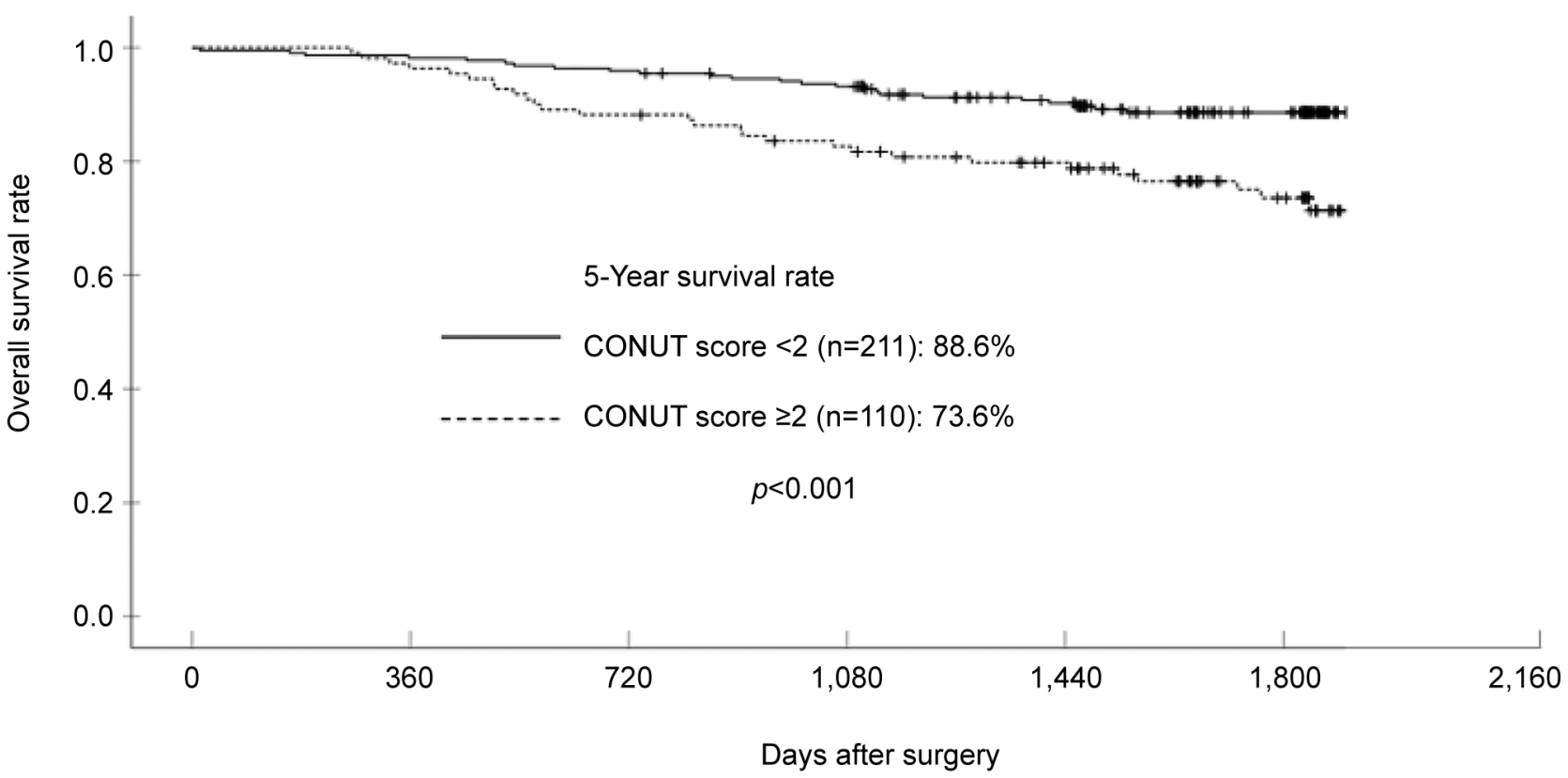

Figure 1. Overall survival of patients according to Controlling Nutritional Status (CONUT) score.

for prognostic significance (Table II). The univariate analyses of factors associated with OS identified $\mathrm{T}$ factor, vascular invasion, lymphatic invasion, lymph node metastasis, and CONUT score as significant prognostic factors. We therefore included the CONUT score in the final multivariate analysis model. The 3- and 5-year OS rates following surgery were $93.6 \%$ and $88.6 \%$, respectively, for the low-CONUT group and $82.7 \%$ and $73.6 \%$ for the highCONUT group $(p=0.022)$. The OS curves are shown in Figure 1. Univariate analyses of factors associated with RFS 
Table III. Univariate and multivariate Cox proportional hazards analysis of clinicopathological factors for recurrence-free survival.

\begin{tabular}{|c|c|c|c|c|c|c|c|c|}
\hline \multirow[b]{2}{*}{ Characteristic } & \multirow[b]{2}{*}{ Subgroup } & \multirow[b]{2}{*}{$\mathrm{n}$} & \multicolumn{3}{|c|}{ Univariate analysis } & \multicolumn{3}{|c|}{ Multivariate analysis } \\
\hline & & & OR & $95 \% \mathrm{CI}$ & $p$-Value & OR & $95 \% \mathrm{CI}$ & $p$-Value \\
\hline \multirow[t]{2}{*}{ Age } & $<65$ Years & 237 & 1.000 & & & & & \\
\hline & $\geq 65$ Years & 94 & 1.283 & $0.702-2.346$ & 0.418 & & & \\
\hline \multirow[t]{2}{*}{ Gender } & Male & 219 & 1.000 & & & & & \\
\hline & Female & 112 & 1.234 & $0.700-2.177$ & 0.467 & & & \\
\hline \multirow[t]{2}{*}{ Pathological type } & Intestinal & 172 & 1.000 & & & & & \\
\hline & Diffuse & 159 & 1.501 & $0.889-2.533$ & 0.129 & & & \\
\hline \multirow[t]{2}{*}{ Pathological T status } & $\mathrm{T} 1$ & 206 & 1.000 & & & & & \\
\hline & $\mathrm{T} 2$ to $\mathrm{T} 4$ & 125 & 3.608 & $2.092-6.224$ & $<0.001$ & & & \\
\hline \multirow[t]{2}{*}{ Lymph node metastasis } & Negative & 233 & 1.000 & & & 1.000 & & \\
\hline & Positive & 98 & 4.462 & $2.622-7.592$ & $<0.001$ & 3.119 & $1.757-5.536$ & $<0.001$ \\
\hline \multirow[t]{2}{*}{ CONUT score } & $<2$ & 221 & 1.000 & & & 1.000 & & \\
\hline & $\geq 2$ & 110 & 2.450 & $1.456-4.121$ & $<0.001$ & 1.713 & $1.000-2.933$ & 0.050 \\
\hline \multirow[t]{2}{*}{ Lymphatic invasion } & Negative & 226 & 1.000 & & & & & \\
\hline & Positive & 105 & 2.945 & $1.746-4.967$ & $<0.001$ & & & \\
\hline \multirow{2}{*}{ Vascular invasion } & Negative & 192 & 1.000 & & & 1.000 & & \\
\hline & Positive & 139 & 3.220 & $1.856-5.589$ & $<0.001$ & 2.100 & $1.168-3.775$ & 0.013 \\
\hline \multicolumn{2}{|c|}{ Postoperative complications } & No & 281 & 1.000 & & & & \\
\hline & Yes & 50 & 1.304 & $0.722-1.394$ & 0.323 & & & \\
\hline
\end{tabular}

CI: Confidence interval; CONUT: Controlling Nutritional Status; OR: odds ratio.

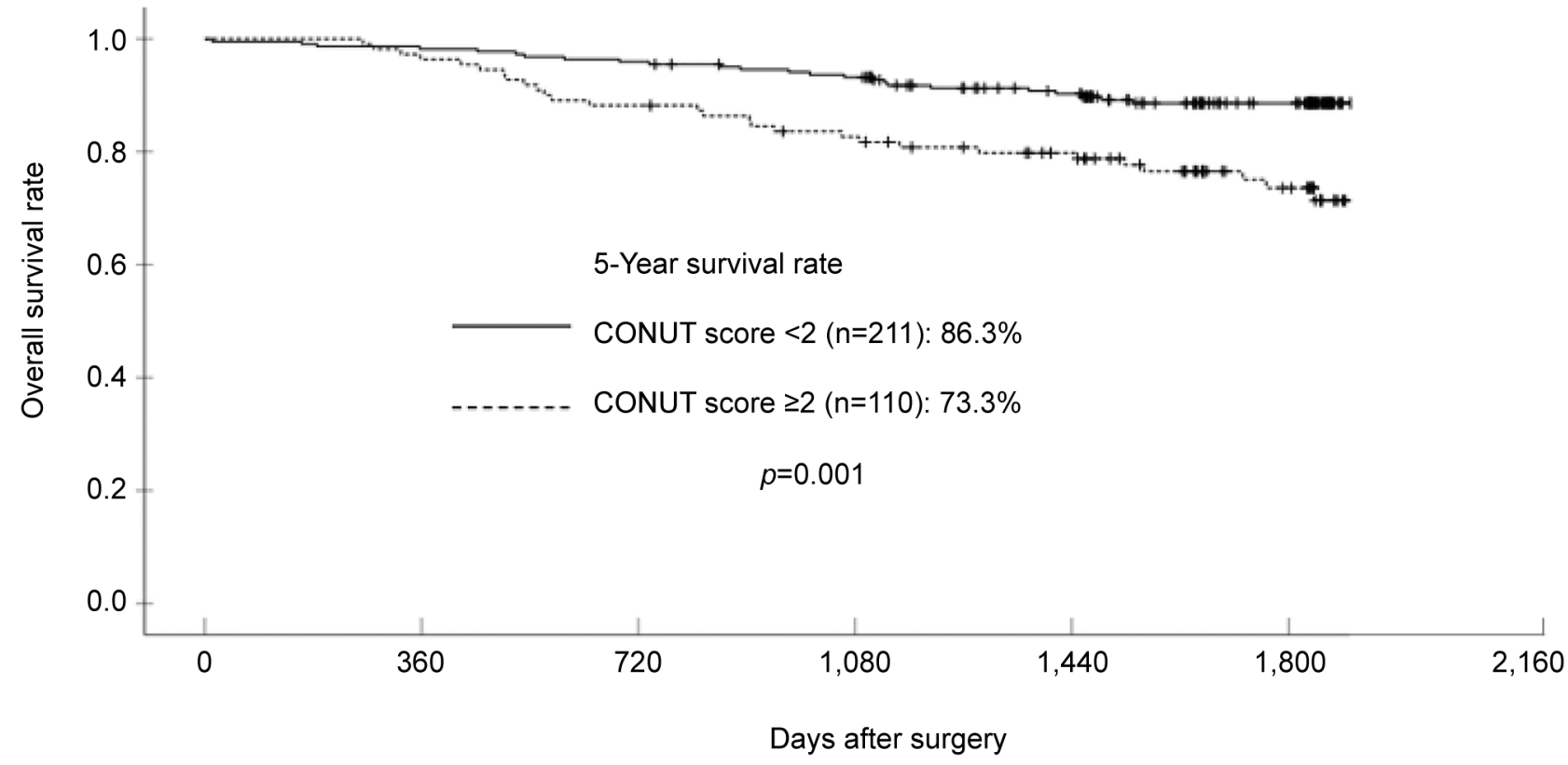

Figure 2. Recurrence-free survival of patients according to Controlling Nutritional Status (CONUT) score.

revealed that the CONUT score was a significant prognostic factor. This was therefore included as a significant prognostic factor in the final multivariate analysis model (Table III). The 3- and 5-year RFS rates after surgery were $78.8 \%$ and $68.7 \%$, respectively, in the low-CONUT group, and $89.3 \%$ and $86.6 \%$ in the high-CONUT group ( $p=0.05)$. The RFS curves are shown in Figure 2. When first relapse was compared between the two groups (Table IV), the incidence of local recurrence tended to be higher in the high-CONUT group. 
Table IV. Patterns of recurrence for patients with Controlling Nutritional Status (CONUT) score $<2$ and those with score $\geq 2$.

\begin{tabular}{lcccc}
\hline & \multicolumn{3}{c}{ CONUT score, $\mathrm{n}(\%)$} \\
\cline { 3 - 4 } Recurrence site & $\begin{array}{c}\text { All cases } \\
(\mathrm{n}=331), \\
\mathrm{n}(\%)\end{array}$ & $\begin{array}{c}<2 \\
(\mathrm{n}=221)\end{array}$ & $\begin{array}{c}\geq 2 \\
(\mathrm{n}=110)\end{array}$ & \\
& 17 -Value & \\
\hline Peritoneal & $15.1 \%)$ & $10(4.5 \%)$ & $7(6.4 \%)$ & 0.487 \\
Hematological & $7(2.1 \%)$ & $5(2.3 \%)$ & $2(1.8 \%)$ & 0.783 \\
Lymph node & $8(2.4 \%)$ & $4(1.8 \%)$ & $4(3.6 \%)$ & 0.315 \\
Local & $8(2.4 \%)$ & $3(1.4 \%)$ & $5(4.5 \%)$ & 0.078 \\
\hline
\end{tabular}

The postoperative treatment course. There were some differences in the incidence of postoperative surgical complications between the high- and low-CONUT groups. With regard to surgical complications, there was a marginally significant difference in the incidence of postoperative bleeding, with the rate being higher in the high-CONUT group. The incidence of postoperative bleeding was $0.5 \%$ in low-CONUT group, while $2.7 \%$ in highCONUT group ( $p=0.074)$. On the other hand, there were no differences in adjuvant treatment course. In the present study, $29.9 \%(99 / 331)$ of patients needed postoperative adjuvant chemotherapy. The percentage of patients who required postoperative adjuvant chemotherapy in the low-CONUT and high-CONUT groups was similar, at $29.0 \%$ (64/221) and $31.8 \%(35 / 110)$, respectively $(p=0.593)$. Among these patients, the percentage of patients who received postoperative adjuvant chemotherapy was also similar, at $83.1 \%(54 / 65)$ and $80.0 \%(28 / 35)$, respectively $(p=0.581)$.

\section{Discussion}

The present study explored whether or not the CONUT score clinically influenced the OS and RFS of patients who underwent curative gastrectomy followed by adjuvant treatment. The major finding was that the CONUT score was an independent risk factor for both OS and RFS. In addition, the CONUT score was closely related to postoperative surgical complications. Thus, the CONUT score was considered a promising clinical prognostic marker for patients who received curative treatment for gastric cancer.

In the present study, the hazard ratio (HR) of the CONUT score for OS was $1.949[95 \%$ confidence interval $(\mathrm{CI})=1.100-3.451, p=0.022]$, and that for RFS was 1.713 (95\% CI $=1.000-2.933, p=0.050)$. Similar results have been observed for other types of gastrointestinal cancer $(21,22)$. Toyokawa et al. evaluated whether or not the preoperative CONUT score was a prognostic factor in 183 esophageal cancer patients (21). Among 183 patients, 168 were assigned to the low-CONUT group and 17 were assigned to the high-
CONUT group. The 3- and 5-year OS rates were $72.0 \%$ and $63.6 \%$, respectively, in the low-CONUT group, and $35.3 \%$ and $35.3 \%$ in the high-CONUT group $(p<0.001)$. The multivariate analysis showed that a high-CONUT score was associated with a significantly poorer $\mathrm{OS}(\mathrm{HR}=2.303,95 \%$ $\mathrm{CI}=1.191-4.455, p=0.013)$. They concluded that the preoperative CONUT score was a prognostic marker for OS in patients who received curative treatment for esophageal cancer. In addition, Iseki et al. clarified the clinical influence of the preoperative CONUT score in 204 patients with colorectal cancer (22). Among 204 patients, 150 were assigned to the low-CONUT group and 54 to the highCONUT group. The 5-year recurrence-free survival rate was $73.0 \%$ in the low-CONUT group and $53.6 \%$ in the highCONUT group $(p=0.0018)$. The 5 -year cancer specific survival rate was $92.7 \%$ in the low-CONUT group and $81.0 \%$ the high-CONUT group ( $p=0.0016)$. The multivariate analysis showed that a high-CONUT score was associated with significantly poorer cancer specific survival $(\mathrm{HR}=4.212$, 95\% CI=1.215-13.350, $p=0.025)$. They concluded that the preoperative CONUT score was a useful marker for the management of patients with colorectal cancer. Given these findings, the CONUT score may be a cost-effective and broadly available prognostic marker for gastrointestinal cancer treatment.

Why did the CONUT score influence the survival of patients with gastrointestinal cancer, including gastric cancer? There are several possible explanations. Firstly, there may be a relationship between the CONUT score and postoperative surgical complications. In the present study, the incidence of postoperative bleeding tended to higher in the low-CONUT group. Similar results were observed in the previous studies. Yoshida et al. evaluated the relationship between the CONUT score and postoperative surgical complications in 352 esophageal cancer patients (23). They divided 352 patients into four groups according to CONUT score (normal: CONUT score $0-1, \mathrm{n}=205$; light: CONUT score 2-4, $n=126$; moderate: CONUT score 5-8, $n=20$; and severe: CONUT score $9-10, n=1$ ). They found that there was a significant relationship between the CONUT score and postoperative surgical complications. The incidence of postoperative surgical complications (any) was $35.6 \%$ in the normal group, $39.7 \%$ in the light group, and $61.9 \%$ in the moderate to severe group, which were statistically significant differences $(p=0.024)$. The incidence of Clavien-Dindo classification grade IIIb or more postoperative surgical complications was $10.2 \%$ in the normal group, $7.9 \%$ in the light group, and $23.8 \%$ in the moderate to severe group, which was also statistically significant $(p=0.034)$. Furthermore, the CONUT score was an independent risk factor for postoperative complications in patients with colorectal cancer (odds ratio: $2.75,95 \% \mathrm{CI}=1.081-7.020$, $p=0.034$ for any surgical complications, and $3.07,95 \%$ 
$\mathrm{CI}=1.002-9.432, \quad p=0.049$ for postoperative surgical complications Clavien-Dindo classification $\geq$ IIIb). The second possible explanation is that there may be a relationship between the CONUT score and the preoperative inflammation status. In the present study, there were significant differences between the low-CONUT and highCONUT groups in the preoperative C-reactive protein status and pre-albumin status. The operative inflammation status and other nutritional status were significantly worse in the high-CONUT group. Previous studies showed that the CONUT score was strongly related to the inflammation status. Recent studies showed that tumor cells directly and/or directly affect host inflammatory cells. These host inflammatory cells promote tumor growth through the regulation of the promotion of angiogenesis, cytokine activity, and the inhibition of apoptosis (24). In addition, an elevated inflammatory response due to tumor cell activity during the perioperative period was also related to poor oncological outcomes in gastrointestinal cancer (25). However, the underlying mechanism is unclear. Thus, further studies should focus on this issue. On the other hand, we hypothesized that there may be some clinical relationship between the CONUT score and postoperative adjuvant treatment. However, there was no relationship between the CONUT score and the introduction of adjuvant treatment or toxicity. Further studies should be undertaken to clarify the relationship between the CONUT score and adjuvant treatment.

The cut-off value of the CONUT score was 2 in the present study. We set this cut-off according to 3- and 5-year overall survival rates. To apply the CONUT score to the clinical setting in gastric cancer treatment, it will be necessary to determine set the optimal cut-off value. Previous studies have set cut-off values of the CONUT score for gastrointestinal cancer. Hirahara et al. evaluated the clinical influence of the CONUT score in 148 patients with esophageal cancer who underwent curative surgery between 2002 and 2014 (26); they set the cut-off value at 1. Toyokawa et al. evaluated the clinical influence of the CONUT score in 185 patients with esophageal cancer who underwent curative surgery (22); they set the cut-off value at 3 based on a receiver operating characteristic curve analysis. In addition, Iseki et al. evaluated the clinical influence of the CONUT score in 204 colorectal cancer patients (19), using a cut-off value of 3 . Differences in the cut-off value of the CONUT score may have occurred due to patient background characteristics, perioperative treatment, or the number of patients. Further studies are needed in order to establish the optimal cut-off value for the CONUT score for patients with gastric cancer.

In conclusion, the preoperative CONUT score was a significant prognostic factor for patients with gastric cancer who underwent gastrectomy and adjuvant treatment. The preoperative CONUT score is a promising and potentially useful tool for developing treatment strategies to optimize the treatment of gastric cancer.

\section{Conflicts of Interest}

The Authors declare no conflicts of interest in association with the present study.

\section{Authors' Contributions}

T. Aoyama and M. Nakazano made substantial contributions to the concept and design. K. Komori, K. Kazama, I. Hashimoto, M. Nakazono, K. Hara, H. Tamagawa, and K. Segami made substantial contributions to the acquisition of data and the analysis and interpretation of data. K. Kano, S. Nagasawa, N. Yukawa, T. Ogata, Y. Rino, and T. Oshima were involved in drafting the article or revising it critically for important intellectual content. All Authors gave their final approval of the version to be published.

\section{Acknowledgements}

This work was supported by JSPS KAKENHI Grant Number $21 \mathrm{~K} 08688$.

\section{References}

1 Bray F, Ferlay J, Soerjomataram I, Siegel RL, Torre LA and Jemal A: Global cancer statistics 2018: GLOBOCAN estimates of incidence and mortality worldwide for 36 cancers in 185 countries. CA Cancer J Clin 68(6): 394-424, 2018. PMID: 30207593. DOI: $10.3322 /$ caac. 21492

2 Smyth EC, Nilsson M, Grabsch HI, van Grieken NC and Lordick F: Gastric cancer. Lancet 396(10251): 635-648, 2020. PMID: 32861308. DOI: 10.1016/S0140-6736(20)31288-5

3 Smyth EC, Verheij M, Allum W, Cunningham D, Cervantes A, Arnold D and ESMO Guidelines Committee: Gastric cancer: ESMO Clinical Practice Guidelines for diagnosis, treatment and follow-up. Ann Oncol 27(suppl 5): v38-v49, 2016. PMID: 27664260. DOI: $10.1093 /$ annonc/mdw350

4 Japanese Gastric Cancer Association: Japanese classification of gastric carcinoma: 3rd English edition. Gastric Cancer 14(2): 101112, 2011. PMID: 21573743. DOI: 10.1007/s10120-011-0041-5

5 Ajani JA, D’ Amico TA, Almhanna K, Bentrem DJ, Chao J, Das P, Denlinger CS, Fanta P, Farjah F, Fuchs CS, Gerdes H, Gibson M, Glasgow RE, Hayman JA, Hochwald S, Hofstetter WL, Ilson DH, Jaroszewski D, Johung KL, Keswani RN, Kleinberg LR, Korn WM, Leong S, Linn C, Lockhart AC, Ly QP, Mulcahy MF, Orringer MB, Perry KA, Poultsides GA, Scott WJ, Strong VE, Washington MK, Weksler B, Willett CG, Wright CD, Zelman D, McMillian N and Sundar H: Gastric cancer, version 3.2016, NCCN clinical practice guidelines in oncology. J Natl Compr Canc Netw 14(10): 1286-1312, 2016. PMID: 27697982. DOI: 10.6004/jnccn.2016.0137

6 Aoyama T, Nakazono M, Nagasawa S and Segami K: Clinical impact of perioperative oral nutritional treatment for body composition changes in gastrointestinal cancer treatment. Anticancer Res 41(4): 1727-1732, 2021. PMID: 33813376. DOI: 10.21873/anticanres.14937 
7 Aoyama T: Perioperative body composition changes in the multimodal treatment of gastrointestinal cancer. Surg Today 50(3): 217-222, 2020. PMID: 31028458. DOI: 10.1007/s00595019-01815-8

8 Aoyama T, Kawabe T, Fujikawa H, Hayashi T, Yamada T, Tsuchida K, Yukawa N, Oshima T, Rino Y, Masuda M, Ogata T, Cho $\mathrm{H}$ and Yoshikawa $\mathrm{T}$ : Loss of lean body mass as an independent risk factor for continuation of $\mathrm{S}-1$ adjuvant chemotherapy for gastric cancer. Ann Surg Oncol 22(8): 25602566, 2015. PMID: 25515199. DOI: 10.1245/s 10434-014-4296-Z

9 Aoyama T, Yoshikawa T, Shirai J, Hayashi T, Yamada T, Tsuchida K, Hasegawa S, Cho H, Yukawa N, Oshima T, Rino Y, Masuda $\mathrm{M}$ and Tsuburaya A: Body weight loss after surgery is an independent risk factor for continuation of S-1 adjuvant chemotherapy for gastric cancer. Ann Surg Oncol 20(6): 20002006, 2013. PMID: 23242818. DOI: 10.1245/s10434-012-2776-6

10 Aoyama T, Sato T, Maezawa Y, Kano K, Hayashi T, Yamada T, Yukawa N, Oshima T, Rino Y, Masuda M, Ogata T, Cho H and Yoshikawa T: Postoperative weight loss leads to poor survival through poor S-1 efficacy in patients with stage II/III gastric cancer. Int J Clin Oncol 22(3): 476-483, 2017. PMID: 28176023. DOI: $10.1007 / \mathrm{s} 10147-017-1089-\mathrm{y}$

11 Aoyama T, Yoshikawa T, Maezawa Y, Kano K, Numata M, Hara K, Komori K, Yamada T, Hayashi T, Sato T, Tamagawa H, Yukawa N, Rino Y, Masuda M, Ogata T, Cho H and Oshima T: The postoperative lean body mass loss at one month leads to a poor survival in patients with locally advanced gastric cancer. $\mathrm{J}$ Cancer 10(11): 2450-2456, 2019. PMID: 31258750. DOI: $10.7150 /$ jca.30697

12 Kushiyama S, Sakurai K, Kubo N, Tamamori Y, Nishii T, Tachimori A, Inoue $\mathrm{T}$ and Maeda K: The preoperative Geriatric Nutritional Risk Index predicts postoperative complications in elderly patients with gastric cancer undergoing gastrectomy. In Vivo 32(6): 1667-1672, 2018. PMID: 30348732. DOI: 10.21873/ invivo. 11430

13 Yang D, Zheng Z, Zhao Y, Zhang T, Liu Y and Xu X: Patientgenerated subjective global assessment versus nutritional risk screening 2002 for gastric cancer in Chinese patients. Future Oncol 16(3): 4475-4483, 2020. PMID: 31793364. DOI: 10.2217/ fon-2019-0539

14 Rinninella E, Cintoni M, Raoul P, Pozzo C, Strippoli A, Bria E, Tortora G, Gasbarrini A and Mele MC: Effects of nutritional interventions on nutritional status in patients with gastric cancer: A systematic review and meta-analysis of randomized controlled trials. Clin Nutr ESPEN 38: 28-42, 2020. PMID: 32690170. DOI: $10.1016 /$ j.clnesp.2020.05.007

15 Ignacio de Ulíbarri J, González-Madroño A, de Villar NG, González P, González B, Mancha A, Rodríguez F and Fernández G: CONUT: a tool for controlling nutritional status. First validation in a hospital population. Nutr Hosp 20(1): 38-45, 2005. PMID: 15762418.

16 Harimoto N, Yoshizumi T, Inokuchi S, Itoh S, Adachi E, Ikeda $\mathrm{Y}$, Uchiyama $\mathrm{H}$, Utsunomiya $\mathrm{T}$, Kajiyama $\mathrm{K}$, Kimura $\mathrm{K}$, Kishihara F, Sugimachi K, Tsujita E, Ninomiya M, Fukuzawa K, Maeda T, Shirabe K and Maehara Y: Prognostic significance of preoperative Controlling Nutritional Status (CONUT) score in patients undergoing hepatic resection for hepatocellular carcinoma: a multi-institutional study. Ann Surg Oncol 25(11): 3316-3323, 2018. PMID: 30051372. DOI: 10.1245/s10434-018$6672-6$
17 Zhang Y and Zhang X: Controlling nutritional status score, a promising prognostic marker in patients with gastrointestinal cancers after surgery: A systematic review and meta-analysis. Int J Surg 55: 39-45, 2018. PMID: 29783000. DOI: 10.1016/j.ijsu. 2018.05.018

18 Kuroda D, Sawayama H, Kurashige J, Iwatsuki M, Eto T, Tokunaga R, Kitano Y, Yamamura K, Ouchi M, Nakamura K, Baba Y, Sakamoto Y, Yamashita Y, Yoshida N, Chikamoto A and Baba H: Controlling Nutritional Status (CONUT) score is a prognostic marker for gastric cancer patients after curative resection. Gastric Cancer 21(2): 204-212, 2018. PMID: 28656485. DOI: 10.1007/s10120-017-0744-3

19 Liu X, Zhang D, Lin E, Chen Y, Li W, Chen Y, Sun X and Zhou $\mathrm{Z}$ : Preoperative controlling nutritional status (CONUT) score as a predictor of long-term outcome after curative resection followed by adjuvant chemotherapy in stage II-III gastric Cancer. BMC Cancer 18(1): 699, 2018. PMID: 29954375. DOI: 10.1186/s12885-018-4616-y

20 Japanese Gastric Cancer Association: Japanese gastric cancer treatment guidelines 2018 (5th edition). Gastric Cancer 24(1): 121, 2021. PMID: 32060757. DOI: 10.1007/s10120-020-01042-y

21 Toyokawa T, Kubo N, Tamura T, Sakurai K, Amano R, Tanaka H, Muguruma K, Yashiro M, Hirakawa K and Ohira M: The pretreatment Controlling Nutritional Status (CONUT) score is an independent prognostic factor in patients with resectable thoracic esophageal squamous cell carcinoma: results from a retrospective study. BMC Cancer 16: 722, 2016. PMID: 27599460. DOI: $10.1186 / \mathrm{s} 12885-016-2696-0$

22 Iseki Y, Shibutani M, Maeda K, Nagahara H, Ohtani H, Sugano K, Ikeya T, Muguruma K, Tanaka H, Toyokawa T, Sakurai K and Hirakawa K: Impact of the preoperative Controlling Nutritional Status (CONUT) score on the survival after curative surgery for colorectal cancer. PLoS One 10(7): e0132488, 2015. PMID: 26147805. DOI: 10.1371/journal.pone.0132488

23 Yoshida N, Baba Y, Shigaki H, Harada K, Iwatsuki M, Kurashige J, Sakamoto Y, Miyamoto Y, Ishimoto T, Kosumi K, Tokunaga R, Imamura Y, Ida S, Hiyoshi Y, Watanabe M and Baba H: Preoperative nutritional assessment by Controlling Nutritional Status (CONUT) is useful to estimate postoperative morbidity after esophagectomy for esophageal cancer. World $\mathbf{J}$ Surg 40(8): 1910-1917, 2016. PMID: 27220507. DOI: 10.1007/ s00268-016-3549-3

24 Grivennikov SI, Greten FR and Karin M: Immunity, inflammation, and cancer. Cell 140(6): 883-899, 2010. PMID: 20303878. DOI: $10.1016 /$ j.cell.2010.01.025

25 Balkwill $\mathrm{F}$ and Mantovani A: Inflammation and cancer: back to Virchow? Lancet 357(9255): 539-545, 2001. PMID: 11229684. DOI: $10.1016 / \mathrm{S} 0140-6736(00) 04046-0$

26 Hirahara N, Matsubara T, Hayashi H, Takai K, Nakada S and Tajima Y: Prognostic importance of controlling nutritional status in patients undergoing curative thoracoscopic esophagectomy for esophageal cancer. Am J Ther 25(5): e524-e532, 2018. PMID: 26866437. DOI: 10.1097/MJT.0000000000000414

Received November 15, 2021

Revised December 7, 2021

Accepted December 9, 2021 